\title{
302 Benign neoplasms of the oesophagus
}

A Account for about $25 \%$ of oesophageal neoplasms.

B Smooth muscle tumours are the most common.

C May be regurgitated into the mouth.

D Leiomyomas are readily visualized during endoscopy.

E Dysphagia is uncommon.

\section{Carcinoma of the oesophagus}

A A very high incidence occurs in Bantu tribesmen.

B Tends to develop at sites of normal narrowing.

C May develop in achalasia.

D Cigarette smoking is not a risk factor.

$\mathrm{E}$ Is more common in females.

\section{Management of oesophageal cancer}

A The right colon is the most suitable portion of the colon for interposition.

B The argon laser is a useful tool for vaporization of tumour.

C The Mousseau Barbin tube is pushed through a tumour stricture.

D Radiotherapy is likely to produce radiation corditis.

E Gastrostomy is essential to maintain nutrition after resection.

\section{Oesophageal stricture}

A Is most commonly due to reflux oesophagitis.

B Endoscopy is not required if barium studies reveal a smooth narrowing.

C Shatski's ring can cause narrowing.

D May be caused by ingesting potassium salts.

E Peptic reflux strictures should be bougienaged if causing dysphagia. 